\title{
PAPERS
}

\section{Five year prospective study of the incidence, clinical features, and diagnosis of achalasia in Edinburgh}

\author{
P J Howard, L Maher, A Pryde, E W J Cameron, R C Heading
}

\begin{abstract}
With the increasing availability of manometry, patients with achalasia are often referred at an early stage when they lack the classic features of established disease. A prospective five year study of the presenting features of untreated achalasia referred to our department was undertaken. Twenty men and 18 women presented throughout adult life, with a mean age at the time of diagnosis of 44 years (range 17 to 76 years). The presenting symptoms were dysphagia: for solids (100\%) and for liquids (97\%), chest pain (74\%), and weight loss (60\%). Endoscopy was reported as normal in 15 patients and achalasia was suggested in only 21 of 33 barium examinations. Fourteen had been treated for gastrooesophageal reflux but none had been misdiagnosed as having cardiac or psychiatric disease. The annual incidence of achalasia in the Lothian region is $0 \cdot 8 / 100000$ of population. Persistent dysphagia is the cardinal symptom of achalasia which presents throughout adult life. Nevertheless, recent onset achalasia is often misdiagnosed as gastrooesophageal reflux disease. Because endoscopy is frequently normal and the diagnosis is often not made by radiology, manometric investigation is necessary if the condition is to be recognised and treated at an early stage.
\end{abstract}

(Gut 1992; 33: 1011-1015)

Achalasia is a rare primary oesophageal motor disorder caused by degeneration or dysfunction of the inhibitory innervation of the oesophageal smooth muscle resulting in incomplete relaxation of the lower sphincter and absent peristalsis in the oesophageal body. It can present at any age although it presents mainly from middle age onwards. ${ }^{1-4}$ The common presenting complaints

Department of Medicine, Royal Infirmary of Edinburgh, Edinburgh P J Howard

L Maher

A Pryde

R C Heading

Cardiothoracic Unit, City Hospital, Edinburgh E W J Cameron

Correspondence to: Dr P J Howard MD MRCP Lecturer in Medicine, Department of Medicine, Royal Infirmary of Edinburgh Royal Infirmary of Edin
Edinburgh EH3 9YW. Edinburgh EH3 9YW. 11 November 1991

Characteristics of pain in patients with achalasia $(n=28)$ at the time of diagnosis are: dysphagia (82-100\% of patients), postprandial and/or nocturnal regurgitation (59-64\%), weight loss (30-91\%), chest pain (17-95\%), and cough (11-46\%). ${ }^{s-15}$ Diagnosis is often delayed, however, with the mean duration of symptoms before treatment reported to be from 4.5 to $7 \cdot 6$ years. ${ }^{5-13}$

We suspected that a growing proportion of patients with achalasia are now being referred at an early stage of the disease and that those with recent onset or 'early' achalasia lack the presenting features of established or 'classic' achalasia. To test this hypothesis, we undertook a prospective study of the presenting features of untreated achalasia patients referred to us between the beginning of July 1986 and the end of June 1991. The annual incidence of achalasia in our catchment population over the same period was estimated.

\section{Methods}

\section{PATIENTS}

All new patients referred for oesophageal manometry between the beginning of July 1986 and the end of June 1991 were examined prospectively. Immediately before the manometric study, the patients' history was taken using a structured questionnaire including specific questions on the nature and duration of the presenting symptoms, complications, and previous treatment. The results of any previous investigations of their symptoms - for example, endoscopy or radiological studies - were also noted.

\section{MANOMETRY AND pH MONITORING}

Oesophageal manometry was performed using an Arndorfer catheter and a standard tech-

\begin{tabular}{|c|c|c|c|c|c|c|}
\hline $\begin{array}{l}\text { Site of origin } \\
\text { Radiation } \\
\text { Quality } \\
\text { Aggravating factors } \\
\text { Relieving factors } \\
\text { Maximum duration } \\
\text { Frequency }\end{array}$ & $\begin{array}{l}\text { Epigastric } \\
6 \\
\text { None } \\
20 \\
\text { Pain/discomfort } \\
15 \\
\text { Eating } \\
19 \\
\text { Eating } \\
1 \\
<5 \text { min } \\
14 \\
>7 \text { episodes } \\
9 \text { per week }\end{array}$ & $\begin{array}{l}\text { Retrosternal } \\
20 \\
\text { Retrosternal } \\
3 \\
\text { Burning } \\
5 \\
\text { Drinking } \\
12 \\
\text { Drinking } \\
8 \\
5-10 \text { min } \\
7 \\
1-6 \text { episodes } \\
\text { per week } \\
13\end{array}$ & $\begin{array}{l}\text { Interscapular } \\
1 \\
\text { Interscapular } \\
6 \\
\text { Sharp } \\
4 \\
\text { Posture } \\
3 \\
\text { Antacids } \\
3 \\
10-30 \text { min } \\
5 \text { - } 1-3 \text { episodes } \\
5 \text { per month }\end{array}$ & $\begin{array}{l}\text { Throat/jaw } \\
1 \\
\text { Throat/jaw } \\
2 \\
\text { Tight stabbing } \\
3 \\
\text { Exercise } \\
0 \\
\text { GTN/nifedipine } \\
3 \\
>120 \text { min } \\
2 \\
<1 \text { episode } \\
1 \text { per month }\end{array}$ & $\begin{array}{l}\text { Arms } \\
0 \\
\text { Arms } \\
1 \\
\text { Wind } \\
1 \\
\text { None known } \\
4 \\
\text { Regurgn/burp } \\
4\end{array}$ & $\begin{array}{l}\text { None known } \\
6\end{array}$ \\
\hline
\end{tabular}


nique. ${ }^{16}$ Achalasia was defined as incomplete relaxation of the distal sphincter with synchronous contractions only in the distal oesophagus in response to water swallows. ${ }^{16}$ Ambulatory $\mathrm{pH}$ monitoring was carried out as previously described $^{17}$ in 14 patients who had been treated with an $\mathrm{H}_{2}$ receptor blocker, gave a history of heartburn or prolonged chest pain and/or had endoscopic oesophagitis. A total acid exposure time of $7 \%$ of recording time was regarded as abnormal. ${ }^{18}$

ESTIMATION OF THE INCIDENCE OF ACHALASIA

The age structure and population size of the Lothian region between 1986 and 1991 was taken from the projected population data issued by the General Register Office for Scotland based upon the 1981 Census. ${ }^{19}$ The total number of patients diagnosed as having achalasia and/or treated for this was obtained from our departmental records, the Lothian Area Surgical Audit and the Thoracic Surgical Unit, City Hospital, Edinburgh. From these data the average yearly age and sex specific incidence of achalasia was calculated. (To ensure complete data collection, endoscopy records were examined at the Western General Hospital and the gastroenterologists in Edinburgh were asked about their referral practice for patients with achalasia. Over the period of the study all new patients seen by physicians had been referred for manometry before treatment and only two patients had undergone Heller's myotomy without manometry).

\section{Results}

\section{PATIENT CHARACTERISTICS AND DURATION OF SYMPTOMS}

Of 600 patients referred for oesophageal manometry between the beginning of July 1986 and the end of June 1991, there were $36(6 \cdot 3 \%)$ (20 men and 18 women) who fulfilled the manometric criteria for achalasia and who had not previously undergone myotomy or pneumatic dilatation. Figure 1 shows the age at onset of symptoms and at diagnosis. The mean age at onset of symptoms was $41 \cdot 2$ years with an even distribution throughout the age range five to 74 years. The mean age at diagnosis by manometry was 44.0 (range 17 to 76 years). Twenty five patients were tertiary referrals from other hospitals of whom 15 were referred by physicians, six by general surgeons and four by cardiothoracic surgeons. Thirteen patients were referred directly by their general practitioners. The possibility of achalasia was specifically mentioned in the referral letters of 22 of 38 patients before manometry. The referral letters of the remaining 16 patients made reference to the possibility of a motility disorder (unspecified) as the basis of symptoms. Conversely, referring clinicians clearly suspected achalasia in only two (of 600) patients who did not have achalasia. One had diffuse oesophageal spasm and the other a gastric carcinoma at the cardia which had been missed by previous endoscopy and radiology.

The median time from the onset of symptoms to a diagnosis of achalasia was $19 \cdot 5$ months (interquartile range $11 \cdot 2$ to $33 \cdot 5$ ). The median time between the first hospital consultation and the manometric diagnosis of achalasia was 3.5 months (interquartile range 2.0 to $9 \cdot 5$ ). One patient was pregnant at the time of diagnosis (and subsequent treatment) and another had Crohn's disease. Two patients had a history of malignant disease. One with a six year history of dysphagia had undergone mastectomy five years before the diagnosis of achalasia and one developed dysphagia three months after a successful left lower lobectomy for a primary lung adenocarcinoma. Two patients had valvular heart disease and two had asthma. Only one patient had been previously treated for psychological illness (depression) and was on treatment with amytriptyline. Seven patients had been prescribed an $\mathrm{H}_{2}$ receptor blocker for suspected gastrooesophageal reflux disease and a further eight patients had taken antacids for relief of symptoms.

\section{SYMPTOMS}

\section{Dysphagia}

All patients complained of dysphagia for solids. Thirty seven patients also complained of difficulty in swallowing liquids but all regarded the solid dysphagia as a greater and more frequent problem. Dysphagia for liquids only became a significant problem when solid dysphagia was marked. Two patients had required hospital admission for bolus obstruction. The clinical course of the dysphagia was variable. At the time of manometry, 19 patients described their dysphagia as becoming more troublesome, 14 said it was stable in frequency and severity and five said that it was improving. (One of these had recently started treatment with nifedipine). Twenty three patients reported loss of weight. There was no significant difference in the median duration of dysphagia in those with, or without, weight loss (19.5 months (interquartile range 12.0 to 24.0 ) and 19.0 months (interquartile range 10.7 to $38 \cdot 0$ ), respectively). Eight patients showed some radiological evidence of oesophageal dilatation within two years of the onset of symptoms.

\section{Pain}

Twenty eight patients complained of pain. The characteristics of the pain in these 28 patients are shown in the Table. The pain was usually short lived with a maximum duration of 10 minutes in $75 \%$ of patients and was variously described as being like wind, a knot, sharp, stabbing, burning or tight. Nine patients said that the pain occasionally woke them from sleep at night; four of these gained relief from antacids or cimetidine.

In all 28 patients the pain began in the midline in the epigastrium, chest, throat or interscapular region and radiated in only a minority (28\%) of patients. The main sites of radiation were the interscapular region, chest, and throat. Radiation into the arms occurred in only one patient. Eating was the major aggravating factor for the pain in 19 patients but only relieved it in 
one. Drinking could either exacerbate or relieve the pain. The pain sometimes occurred without any obvious cause ('spontaneous pain') in eight patients but the pain was exclusively 'spontaneous' in only four patients. Six patients were unable to identify any specific relieving factors. The pain was never exacerbated by exercise or relieved by rest and in no case had it been thought to be angina either by patients or doctors. None of the patients had undergone exercise electrocardiography testing, coronary arteriography or had been referred to a cardiologist. Nifedipine or glyceryl trinitrate, prescribed to five patients with presumed 'vigorous achalasia' or 'oesophageal spasm,' relieved the pain in only three.

Seven patients had been treated for gastrooesophageal reflux with an $\mathrm{H}_{2}$ receptor blocker and an additional eight with antacids. While heartburn was described by five patients, however, only one patient complained of a retrosternal burning pain that was related to posture, sometimes caused nocturnal waking and was relieved by antacids. This patient did, indeed, have a markedly abnormal supine acid exposure time ( $43 \%$ of recording time) during oesophageal pH monitoring. The other patient who experienced prolonged episodes of pain of up to two hours, also had nocturnal pain and an abnormal supine acid exposure time of $52 \cdot 7 \%$.

\section{INVESTIGATIONS}

\section{Endoscopy}

Although undertaken in all patients before treatment, only 34 patients underwent endoscopy before manometry. The endoscopic findings were reported as consistent with achalasia in only 10 patients. The findings reported by the endoscopists in the others were: normal (15 patients); oesophagitis (three); oesophagitis and stricture (one); bolus impaction (one); external compression from an enlarged left atrium (one); hiatus hernia (one) and possible oesophageal dysmotility (two). Of the patients undergoing endoscopy in our unit $23 \%$ were thought to have achalasia compared with $38 \%$ undergoing endoscopy at the referring hospital (this difference is not statistically significant).

\section{Barium swallow}

Radiology was carried out in 33 patients before manometry. The radiographic appearances were reported as consistent with achalasia in 15 patients and suggestive of achalasia in a further seven. The others were reported as: stricture (two); gastrooesophageal reflux (one); oesophageal web (one); unexplained hold up at the gastrooesophageal junction (one); tertiary contractions (two); food impaction (two); normal (two). There was no difference in the median duration of symptoms in patients for whom a correct diagnosis of achalasia was made or suspected radiologically when compared with those in whom the radiological diagnosis was incorrect $(18.5$ months (interquartile range 11 to 24.5) compared with 15 months (interquartile range $12 \cdot 1$ to $60 \cdot 5$ ), respectively). Of those

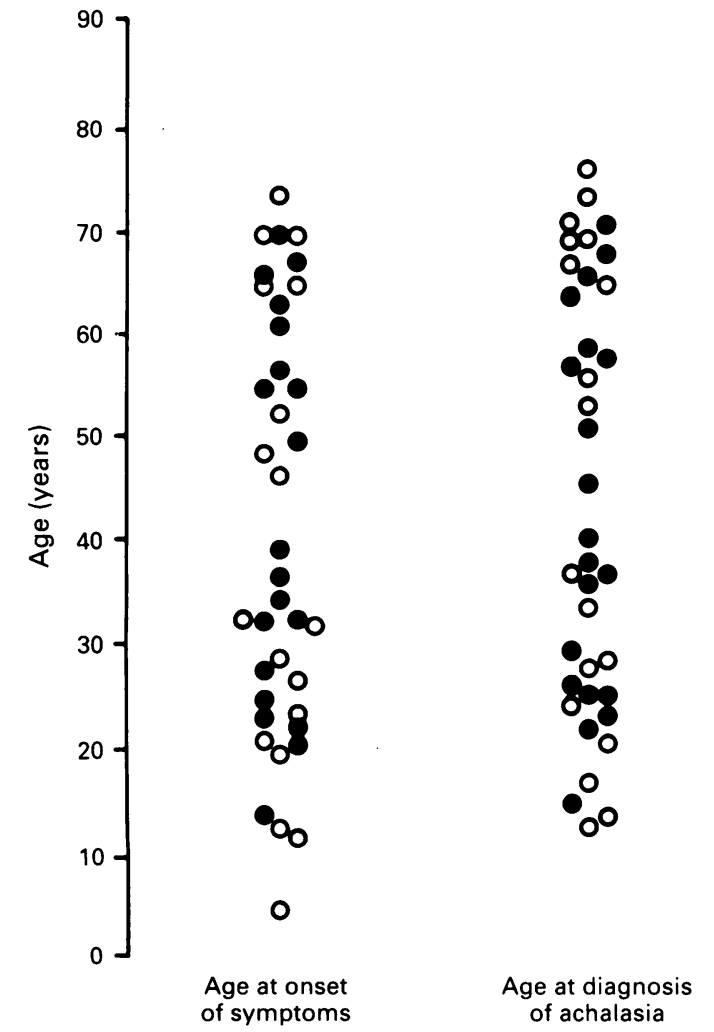

Figure 1: Age at onset of symptoms and age at diagnosis in achalasia patients. Women are denoted by open circles and men by closed circles.

undergoing radiology in our hospital, 12 of 13 barium examinations were reported as consistent with achalasia, compared with only 10 of 20 examinations carried out at other hospitals $(\mathrm{p}<0.05)$.

\section{Manometry}

Manometry was undertaken in all patients. Two patients were initially found to have diffuse oesophageal spasm (with $30 \%$ and $80 \%$ synchronous contractions respectively in response to water swallows). Worsening symptoms led to reinvestigation 36 and 48 months later respectively and the manometric studies then showed achalasia.

\section{Ambulatory pH monitoring}

Ambulatory $\mathrm{pH}$ monitoring was carried out in 14 patients. One patient who experienced vomiting during the $\mathrm{pH}$ recording, had abnormal upright acid exposure $(52 \cdot 7 \%$ of recording time), two had abnormal supine reflux $(43 \cdot 2 \%$ and $52 \cdot 7 \%)$ and one had abnormal combined erect and supine reflux ( $23.4 \%$ erect and $100 \%$ supine). In all cases abnormal acid exposure was caused by delayed acid clearance, rather than frequent reflux episodes. In one additional patient prolonged upright acid exposure $(6 \cdot 4 \%)$ was clearly the result of the ingestion of Coca Cola.

\section{INCIDENCE OF ACHALASIA}

Twenty five of the 38 patients presenting during the five year period of the study were resident within the Lothian region. Two additional 
Annual age specific incidence of achalasia in Lothian (per 100000 population)

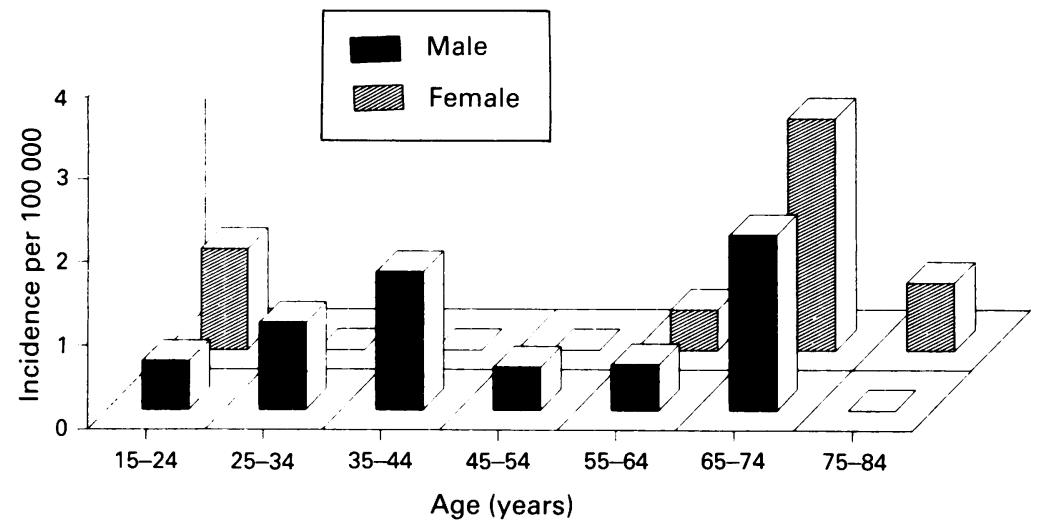

Figure 2: Age and sex specific incidence of achalasia per 100000 population in the Lothian region. incidence in middle age. Second, rapid progression to the stage of oesophageal dilatation and weight loss may occur in young adults within two years of their first symptoms. Conversely, achalasia presenting in old age is not usually associated with a long duration of symptoms. Only one of our patients described a long (20 year) history of dysphagia. Third, we found that only two of 36 patients presented acutely to hospital with bolus impaction and most complained of a gradual onset of solid and liquid dysphagia, which often pursued a variable course. At the time of manometry, less than half the patients complained of worsening dysphagia. Twenty three $(60 \%)$, however, had experienced weight loss, although patients with this complication did not have a significantly longer history of dysphagia than those without weight loss. None of our patients had any of the respiratory, arthritic, or neoplastic complications described by Ellis.

In contrast with the experience of Stacher

Lothian residents were identified who had undergone Heller's myotomy at the City Hospital in 1986, without preoperative manometry. Therefore, 25 of 27 (93\%) achalasia patients within the Lothian region had undergone manometric assessment, although in the last three years all new patients had been referred for motility studies. Hence, the overall incidence of achalasia was $0 \cdot 81 / 100000$ population over the age of 15 years $(0.80$ for men and $0.83 / 100000$ for women). The age and sex specific incidence of achalasia is shown in Figure 2. Achalasia occurs throughout adult life without any apparent increase in incidence after middle age. Figure 2 raises the possibility of a bimodal distribution in incidence in woman with early and late peaks with few cases in middle age. The numbers are small, however, and this pattern is less obvious from Figure 1.

\section{Discussion}

To our knowledge this is the first prospective study of the presenting symptoms of untreated achalasia in which the patients' symptoms were systematically documented before the manometric diagnosis was made. One third of the referrals came directly from general practitioners, one third are tertiary referrals from other physicians and one third from surgeons. The median duration of symptoms at diagnosis was 19.5 months. This contrasts with several previous studies in which the mean duration of symptoms before diagnosis was between 4.5 and $7 \cdot 6$ years. $^{5-13}$

In 1960 Ellis $^{20}$ suggested that the natural history of achalasia could be divided into three stages. In stage I (onset), the majority of patients presented acutely with dysphagia, pain, and regurgitation. In stage II (latent period), which often lasted many years, symptoms would pursue a variable course and would often appear to improve. In stage III, patients would present after a long history of dysphagia with weight loss, pulmonary complications and arthritis. Our data, however, show that this view of the natural history of achalasia is not valid in three significant respects. First, achalasia now presents throughout adult life without an increase in et $a l,{ }^{21}$ none of our achalasia patients had been misdiagnosed as having anorexia or bulimia. Only one patient had a psychiatric disorder (depression), which preceded the onset of dyspatients had never been confused with cardiac pain, perhaps because both patients and general practitioners recognised the association with other upper gastrointestinal symptoms and the absence of a clear relationship to exercise.

We suspect that the pain experienced in achalasia is usually a motor pain. Typically, it was short lived ( $<10$ minutes), localised to the midline but with a variable quality. It occasionally occurred 'spontaneously' but more usually was exacerbated by eating and could be either aggravated or relieved by drinking. Some patients, however, may experience gastrooesophageal reflux symptoms and even develop oesophagitis. There would appear to be three mechanisms for this. Smart et al ${ }^{22}$ have shown that some achalasia patients have abnormally prolonged acid exposure times and generate lactic acid from retained residue within the oesophagus. They found, however, that typical reflux episodes in achalasia were uncommon. In our series five of the 15 patients had abnormal acid exposure times caused by delayed clearance of either gastrooesophageal refluxate or of exogenous acid in the form of carbonated drinks (Coca Cola). Poor acid clearance could be a particular problem in early achalasia when sphincter pressure may be lower and relaxation may be greater than in established achalasia. ${ }^{23}$

Achalasia is a rare condition with an incidence in the Lothian region of $0 \cdot 81 / 100000$. Previous estimates of the annual incidences of achalasia per 100000 population are: for Nottingham $0 \cdot 5^{3}$; Cardiff $0 \cdot 4^{24}$; and Minnesota $0 \cdot 6 .{ }^{25}$ More recent incidence figures for Scottish men and women of $1 \cdot 1$ and 1.2 respectively ${ }^{4}$ and in Oxford of 0.9 for both sexes, ${ }^{4}$ however, are in close agreement with our own estimate. Although there are rare well documented genetic syndromes that include achalasia, ${ }^{26}$ Mayberry and Atkinson ${ }^{27}$ failed to find any proven cases in first degree relatives of patients with achalasia. In our own study, the equal sex incidence, absence of family history, phagia by many years. The pain experienced by 
and presentation throughout adult life suggest that achalasia is usually an acquired, rather than inherited disease. In agreement with Rosenzweig and Traube ${ }^{28}$ we found that it was often misdiagnosed as gastrooesophageal reflux disease. Indeed, $20 \%$ of patients had been prescribed $\mathrm{H}_{2}$ blockers and a further $20 \%$ had been given or taken antacids for relief of symptoms.

Endoscopy, rather than radiology, was the investigation of first choice and is mandatory in patients with suspected achalasia to exclude mechanical obstruction and malignancy. There are few signs, however, such as oesophageal dilatation and the presence of food residue within the oesophagus, which suggest a diagnosis of achalasia and these features are not diagnostic. It is our view that endoscopy is not an appropriate means of establishing a diagnosis of achalasia. In our series, less than a third of endoscopies were reported as consistent with achalasia and $44 \%$ were normal. We suspect, however, that a normal or equivocal report or an endoscopy showing oesophagitis may often contribute to delay in making the correct diagnosis. Radiology was undertaken in $85 \%$ of patients, but a confident diagnosis of achalasia was made or suggested in only two thirds of studies. Although we do not have reliable information concerning the experience of the radiologists carrying out these examinations, there was a statistically significant difference in the number of studies reported as consistent with achalasia in our hospital $(92 \%)$ compared with those undertaken at other hospitals $(50 \%)$. The difference may relate to radiologist expertise with this rare condition, but it is also possible that the clinical information given to the radiologists in our hospital more frequently drew attention to the suspicion of achalasia.

A progression from diffuse oesophageal spasm to achalasia was first described in a case report by $\mathrm{Kramer}^{29}$ and was subsequently documented in six patients by Vantrappen et al..$^{30}$ Our finding of progression from diffuse oesophageal spasm to achalasia in two of 38 patients provides further evidence that oesophageal 'spasm' and achalasia are part of the same spectrum of motor disorders. Patients with 'spasm' and significant dysphagia merit further follow up.

In conclusion, achalasia presents throughout adult life. 'Early' achalasia is easily confused with gastrooesophageal reflux disease and the significance of the dysphagia may be overlooked. Endoscopy is frequently normal and the diagnosis is often not made by radiology. We believe that longstanding untreated achalasia with its pulmonary, arthritic, and possibly neoplastic complications should be a phenomenon of the past. If 'early' achalasia is not to be missed, however, it is necessary that patients with persistent unexplained dysphagia, particularly when associated with weight loss, undergo manometric assessment.
1 Clouse RE. Motor Disorders. In: Sleisinger MH, Fordtran JS, eds. Gastrointestinal disease: pathophysiology diagnosis
management. 4th ed. Philadelphia: WB Saunders, 1989: m59-93.

2 Wingate DL. Disorders of motility. In: Wetherall DJ, Ledingham JGG, Warrell DA, eds. Oxford textbook of medicine. 2nd ed. Oxford: Oxford University Press, 1987: $12.37-51$.

3 Mayberry JF, Atkinson M. Studies of the incidence and prevalence of achalasia in the Nottingham area. $Q \mathcal{F} \mathrm{Med}$ prevalence of achat

4 Mayberry JF, Atkinson M. Variations in the prevalence of achalasia in Great Britain and Ireland: An epidemiological study based on hospital admissions. $Q \mathcal{J}$ Med 1987; 62: $67-74$ 5 Sawyers JL, Foster JH. Surgical considerations in the manage-
ment of achalasia of the esophagus. Ann Surg 1967; 165: $780-5$.

6 Grimes OF, Stephens HB, Margulis AR. Achalasia of the esophagus. Am f Surg 1970; 120: 198-202.

7 Vantrappen G, Hellemans J, Deloof W. Treatment of achalasia with pneumatic dilatation. Gut 1971; 12: 268-75.

8 Yon J, Christensen J. An uncontrolled comparison of treatments for achalasia. Ann Surg 1975; 182: 672-6.

9 Black J, Vorbach AN, Collis JL. Results of Heller's operation for achalasia of the oesophagus. The importance of hiatal for achalasia of the oesophagus. The
repair. Br f Surg 1976; 63: 949-53.

10 Menzies-Gow N, Gummer JWP, Edwards DAW. Results of Heller's operation for achalasia of the cardia. Brf Surg 1978; 65: 483-5.

11 Jara FM, Toledo-Pereyra LH, Lewis JW, Magilligan DJ Long-term results of esophagomyotomy for achalasia of esophagus. Arch Surg 1979; 114: 935-6.

12 Okike N, Payne WS, Neufield DM, Bernatz PE, Pairolero PC, Sanderson DR. Esophagomyotomy versus forceful dilataSanderson DR. Esophagomyotomy versus forceful dilata-
tion for achalasia of the esophagus. Results for 899 patients. Ann Thorac Surg 1979; 28: 119-25.

13 Fellows IW, Ogilvie AL, Atkinson M. Pneumatic dilatation in achalasia. Gut 1983; 24: 1020-3.

14 Pai GP, Ellison RG, Rubin JW, Moore HV. Two decades of experience with modified Heller's myotomy for achalasia. Ann Thorac Surg 1984; 38: 201-6.

15 Dellipiani AW, Hewestson KA. Pneumatic dilatation in the management of achalasia: Experience of 45 cases. $Q \mathcal{F}$ Med management of ach

16 Benjamin SR, Richter JF, Cordova CM, Knuff TE, Castell DO. Prospective manometric evaluation with pharmacologic provocation of patients with suspected esophagea motility dysfunction. Gastroenterology 1983; 84: 893-901.

17 Howard PJ, Maher L, Pryde A, Heading RC. Symptomatic gastro-oesophageal reflux, abnormal oesophageal acid exposure, and mucosal acid sensitivity are three separate,
though related, aspects of gastro-oesophageal reflux disease Gut 1991; 32: 128-32.

18 De Caestecker JS. Twenty-four-hour $\mathrm{pH}$ monitoring: advances and controversies. Neth $\mathcal{F}$ Med 1989; 34: S20-39.

19 Projected population of Scotland by area (Based on 198 Census). Edinburgh: General Register Office of Scotland, 1983.

20 Ellis FG. The natural history of achalasia of the cardia. Proc $R$ Soc Med 1960; 53: 663-6.

21 Stacher G, Kiss A, Wiesnagrotzki S, Bergmann H, Hobart J, Schneider C. Oesophageal and gastric motility disorders in patients categorised as having primary anorexia nervosa. $G u$ 1986; 27: 1120-6.

22 Smart HL, Foster PN, Evans DF, Slevin B, Atkinson M Twenty four hour oesophageal acidity in achalasia before and after pneumatic dilatation. Gut 1987; 28: 883-7.

23 Vantrappen G, Hellemans J, Deloof W, Vlembois P, Van denBrucke J. Treatment of achalasia with pneumatic dilatation. Gut 1971; 12: 268-75.

24 Mayberry JF, Rhodes J. Achalasia in the city of Cardiff from 1926 to 1977 . Digestion 1980; 20: 248-52.

25 Earlam RJ, Ellis FH Jr, Nobrega FT. Achalasia of the esophagus in a small urban community. Proc Mayo Clini 1969; 44: 478-83.

26 Stuckey BG, Mastaglia FL, Reed WD, Pullan PT. Glucocorticoid insufficiency, achalasia, alacrima with autonomic and motor neuropathy. Ann Intern Med 1987; 106: 62-4.

27 Mayberry JF, Atkinson M. A study of swallowing difficulties in first degree relatives of patients with achalasia. Thorax 1985; 40: 391-3.

28 Rosenzweig S, Traube $M$. The diagnosis and misdiagnosis of achalasia. 7 Clin Gastroenterol 1989; 11: 147-53.

29 Kramer P, Harris LD, Donaldson RM. Transition from symptomatic diffuse spasm to cardiospasm. Gut 1967; 8: symptom $115-8$.

30 Vantrappen G, Janssens J, Hellemans J. Achalasia, diffuse esophageal spasm, and related motility disorders. Gastroenterology 1979; 76: 450-7. 